\section{HuELLAS, RESIDUOS, CORRESPONDENCIAS: CONTRIBUCIÓN A UNA LECTURA DE LO \\ RELACIONAL EN LITERATURA}

TRACES, RESIDUES, INTERTEXTS:

A CONTRIBUTION TO THE RELATIONAL ASPECTS IN LITERATURE

Norah Giraldi Dei Cas

Université Lille 3

Villeneuve d'Ascq, Lille, França

\title{
Resumen
}

Distinguimos en este trabajo entre la puesta en escena de lo nacional según una dirección y estrategias ideológicas que caracterizan una literatura que acompaña la creación de los estados nacionales, y la modalidad de los desplazamientos reales o imaginarios que asume el artista en su obra, que produce una traducción o modalidad de lo intertextual y extraterritorialidades diversas, y que recupera el lector como búsqueda de huellas y correspondencias entre una o más obras. La literatura como territorio en devenir, que da lugar a relaciones significativas emergentes, según el tipo de recepción. Teniendo en cuenta esta perspectiva, la de los intercambios transnacionales y transoceánicos en el contexto de la globalización actual, bajo la influencia de migraciones masivas, de constantes exilios y otros tipos de pasajes, queremos contribuir a la reflexión sobre una postura crítica de lo relacional que admita estas modalidades de trasvases, traducciones y relaciones múltiples en lo social como en el campo de la creación.

\begin{abstract}
This article attempts to distinguish between national ideologies and the ideological strategies characterizing literatures that accompany the creation of nation-states, and real or imaginary displacements within the artist's works which produce a variety of intertextual and extraterritorial modes or transpositions, engaging the reader in the quest for roots, traces and references within one or several texts.
\end{abstract}

\section{Résumé}

Nous distinguons, dans ce travail, la littérature organisée selon des stratégies idéologiques faisant valoir la place occupée par les Etats nation dans le classement et organisation de l'Histoire littéraire, et la littérature en devenir, aux frontières fluctuantes, induisant des émergents selon les déplacements réels ou imaginaires assumés par les auteurs ou représentés dans leurs œuvres. Les modalités de l'intertextuel y sont
Palabras clave: huellas; correspondencias; crítica relacional; migración y fronteras fluctuantes de la literatura; Darwin; Borges, Tomás de Mattos.
Keywords: Traces; Intertexts; Critical posture of the relational; Migrations and fluctuating boundaries of literature; Darwin; Borges; Tomás de Mattos.

Mots-clés: Traces; Correspondances; Critique relationnelle; Migrations et frontières fluctuantes de la littérature; Darwin; Borges; Tomás de Mattos. 
Literature is viewed here as a territory "in the making" which allows for the emergence of significant relations depending on the nature of reception. From the perspective of transnational and transoceanic exchanges, in the context of present-day globalization with its massive migrations, numerous exiles and other forms of passage, we would like to make a contribution to the reflections on the critical posture of the relational by taking into account these various modes of crossing, translation and multiple relations, both in the social and in the artistic fields. à l'œuvre, aussi bien que les jeux d'extraterritorialité ; ils sont perçus par le lecteur dans sa recherche de traces et correspondances entre une ou plusieurs œuvres. Selon cette perspective, en particulier dans le contexte des échanges transnationaux et transocéaniques de la globalisation actuelle, sous l'influence des migrations massives, des exils et d'autres types de passages, nous souhaitons contribuer à la réflexion portant sur une posture critique du relationnel qui admet ces modalités de transmissions, traductions et relations multiples tant au niveau social que dans le champ de la création.

La investigación actual en el campo de los estudios literarios (programas de investigación, coloquios, tesis...) muestra un interés creciente por la emergencia de nuevos temas y modalidades de escritura que subrayan pasajes, circulación de modelos, lazos que relacionan diferentes tipos de expresión y diferentes representaciones producidas concomitantemente en diferentes rincones del planeta. Este fenómeno que da cuenta de una práctica intertextual no es nuevo; Bakhtine, Julia Kristeva, Gérard Genette, Antoine Compagnon entre muchos otros críticos, definieron las variantes del fenómeno (dialogismo, intertextualidad, rescritura) que se comprueba como modalidad de escritura en diferentes autores. Borges en su diálogo permanente con otros autores, escrituras y modos de pensar denomina "precursor" a escritores como él que leen y reescriben a partir de Dante, Cervantes, Shakespeare... provocando una refracción que lleva a encontrar huellas, sobre todo, significados inadvertidos en el texto "fuente". Lo que emerge del texto "fuente" no está en él; lo que cuenta es el recorrido en Borges, el trazado y el resultado que se produce al escribir sus textos, los desvíos magistrales que él hace intervenir para que los textos de Dante, Cervantes, Shakespeare se parezcan a los suyos. Este fenómeno de emergencia es característico de toda la literatura pero su significación es creciente. Se sigue utilizando la noción de hibrida- 
ción para invocar el resultado, un resultado que se lee como propiedad adquirida, constituyente de un nuevo objeto producto de una mezcla que se considera como una adición o suma de partes según un movimiento de causa a efecto. La percepción de lo emergente en literatura depende del tipo de traducción o traslación que haga el escritor tanto como de la lectura, es decir, de cada lector. Si la mezcla de estilos y de modalidades de escritura siempre existió, y si los procedimientos de de-territorializaciones y re-territorializaciones son moneda corriente en la literatura en todas las épocas, ${ }^{1}$ este fenómeno que se manifiesta como mecanismo de interrelación de literaturas, estéticas y reciprocidades entre escritores, que pueden ser de diferentes momentos y diferentes territorios, produce un comercio con extranjerías, extraterritorialidades que es difícil considerar en su totalidad por sus infinitas y variadas posibilidades de extensión y de diseminación. En la era de la extrema globalización en que vivimos, esta modalidad entra en conflicto con la manera de pensar y estudiar la literatura de manera compartimentada (por temas, en función de periodos, con respecto a un modelo dado como en literatura comparada, divida por naciones y por lenguas). Podemos notar, además, que en muchos casos los escritores que han migrado o que viven entre dos mundos, entre dos o más culturas quedan fuera del canon de la literatura nacional, se vuelven casi invisibles y las huellas de sus desplazamientos e intercambios imaginarios o reales, en relación con otras obras y con otras culturas, los descalifica a menudo dentro del ranking de la literatura nacional y, a menudo también, a nivel internacional. Son pocos los que realmente se imponen, en los dos o tres o más lugares donde han vivido, como Roberto Bolaño en los 90 y Carlos Liscano en la década del 2000. Sin embargo, la literatura de América pasó en pocos años de la cultura Macondo (avatar, variación brillante de una literatura que, habiéndose desprendido de lo regional, se lee hoy día como ideológicamente recuperada por las diferentes literaturas nacionales y la continental) a la literatura de los movimientos que buscaron internacionalizar sus temáticas,

\footnotetext{
${ }^{1}$ Los ejemplos son muchos y algunos de ellos magistrales: Flaubert con Salambo, ambientada en Cartago, inaugura la novela moderna europea, Rubén Darío para aludir a la identidad cultural múltiple de su voz poética en Prosas Profanas, convoca tanto las cortes europeas y sus damas, como la Pompadour, como las culturas africanas e indígenas de América ("Hay en mi sangre alguna gota de sangre de África, o de indio chorotega o nagrandano”).
} 
* (FUGUET, Alberto \& GÓMEZ, Sergio. McOndo, anotología de nueva literatura hispanoamericana. Barcelona: Grijalbo-Mondador, 1996.)

* (GRUZINSKI, Serge. Quelle heure est-il là-bas? Amérique et Islam à l'orée des Temps modernes. Seuil, 2008.) como McOndo, fundado en torno a la antología del mismo nombre, publicada en 1996, por los chilenos Alberto Fuguet y Sergio Gómez* como expresión de la nueva literatura hispanoamericana, y el Manifiesto del Crack, iniciado también en 1996, lanzado en México DF por Ignacio Padilla y Jorge Volpi. ${ }^{2}$

Estos desplazamientos figurados, muchas veces propiamente literarios, metafóricos, dejan huellas en las diferentes modalidades de escritura y en la manera de pensar el sujeto de la escritura. Estos intercambios emergen y nutren la literatura de todos los tiempos, incluso si el autor no cambia de país; este fenómeno de asimilación por la lectura o en procesos de imaginación se (re)produce desde siempre en los textos y se estudia bajo las formas o modos de la intertextualidad. Pero la frecuencia de desterritorializaciones y de reterritorializaciones ha aumentado en nuestra época (o se hace más evidente). Y, hoy día, la cuestión de las transferencias de una literatura migrante, viajera (y no solo de viajeros como en el siglo XIX) vuelve a plantearse con acuidad y evoca maneras de actuar de épocas anteriores, en particular en el Renacimiento, época de los primeros viajes planetarios, de los primeros "descubrimeintos" de una mundialidad de referencias, puntos de vista, conocimientos compartidos o en disputa.*

Frente a la emergencia de una nueva forma del fenómeno de mundialización, que tiene sus antecedentes en la creación de los Estados modernos, lo que me interesa destacar es la posibilidad de leer la literatura como fenómeno de emergencia. ${ }^{3}$ Cada obra es emergente, en primer lugar, porque su totalidad no es reductible a las partes que la constituyen y, en segundo lugar, con respecto a las condiciones de creación, a la relación que establece con otras obras, así como con respecto a la Historia y a la biografía de su autor. La obra es siempre emergente como una sola y múltiple, por no estar sujeta a una linealidad marcada como principio de predictibilidad y porque no es el resultado de una relación de causa a efecto. El todo (lo que podemos percibir en la lectura) no sería la resultante de cada una de las partes sino que, ausente de ellas, es algo nuevo

${ }^{2}$ El Movimiento del Crack duró muy pocos años; se caracterizó por postular la ruptura con los escritores del Boom, escribir para un reducido número de lectores sin tema definido pero con una propuesta estética de lo grotesco para caricaturizar la realidad dislocada.

${ }^{3}$ Sobre la noción de "emergencia" cf. MALHER \& BUNGE. Foundations of Biophilosophy. Berlin: Spring, 2005 y SÈVE, Lucien. Emergence, complexité et dialectique. Paris: Odile Jacob, 2005. 
que se comprende por medio de la doble operación de complétude y partitude, * tanto a nivel de las partes (las obras) como a nivel del todo leído o estudiado como tal. Así podría aplicarse la noción de emergencia a la complejidad que significa la literatura, a su manera de construir un continuum de manifestaciones que se refiere a las facultades de cada unidad que lo compone (obras) pero sin repetirse nunca y sin funcionar de manera lineal o aditiva. Una emergencia que se descubre según la mirada del sujeto lector que se reconoce, o reconoce algo nuevo, en la novedad resultante. La literatura que Borges figura con la "Biblioteca de Babel" dibuja esta relación dialéctica a la que apuntamos, del todo con respecto a las partes, lo que me lleva a decir, como premisa, que es imposible comprender la emergencia del fenómeno literario actual sin tener en cuenta sus antecedentes y las variaciones con respecto al todo que construye cada uno de los autores.

Dado el contexto actual, parece más fácil comprender lo que Borges cuestiona y defiende en su conferencia El escritor argentino y la tradición ${ }^{4}$ que la literatura no tenga nacionalidad y que forme un continuum, que no se fije en fronteras de lengua ni de estilos, ni de materiales evocados o convocados en el texto. El patrimonio de un escritor no se reduce a las obras que pertenecen únicamente a la tradición nacional. Borges, en el conocido relato "La Biblioteca de Babel" da una nueva vuelta de tuerca a esta idea, imaginando una sola Biblioteca que es la literatura en su extensión ilimitada, como Orden del universo (el universo que es y está contenido en la literatura):

... la Biblioteca perdurará [comparada, sobre todo, a la especie humana]: iluminada, solitaria, infinita, perfectamente inmóvil, armada de volúmenes preciosos, inútil, incorruptible, secreta. / Acabo de escribir infinita /... Yo me atrevo a insinuar una solución del antiguo problema: La Biblioteca es ilimitada y periódica. Si un eterno viajero la atravesara en cualquier dirección, comprobaría al cabo de los siglos que los mismos volúmenes se repiten en el mismo desorden (que, repetido, sería un orden del Orden).*

\footnotetext{
${ }^{4}$ Borges afirma en "El escritor argentino y la tradición: "Por eso repito que no debemos temer y que debemos pensar que nuestro patrimonio es el universo; ensayar todos los temas, y no podemos concretarnos a lo argentino para ser argentinos: porque o ser argentino es una fatalidad, y en ese caso lo seremos de cualquier modo, o ser argentino es una mera afectación, una máscara” (BORGES, Jorge Luis. Discusión. In: Obras completas. Buenos Aires: Emecé Editores, 1975, tomo I: 273).
}

* (BOHM, David. La danse de l'esprit et le sens déployé. La Varenne-Saint Hilaire: Séveyrat, 1985: 33. Citado por Claude Vautier, "La longue marche de la sociologie relationnelle». In: Nouvelles perspectives en sciences sociales: revue internationale de systémique complexe et d'études relationnelles, vol. 4, $n^{\circ} 1,2008$ : 98. URI: http://id.erudit.org/ iderudit/01964ar. Consultado el 10-3-2013.)

\footnotetext{
* (BORGES, Jorge Luis. La Biblioteca de Babel. Ficciones (1944). In: Obras completas. Buenos Aires: Emecé Editores, 1975, tomo I: 470-471.)
} 
* (AREA, Lelia. Una biblioteca para leer la Nación. Rosario: Beatriz Viterbo Editora, 2006. 358 pp.)

* (Ibidem: 12-15.)
La opción que selecciona la Biblioteca en función de una nacionalidad, de una lengua, de un tema, implica una opción de lectura reduccionista. Esta ha sido, sin embargo, la manera más generalizada de seleccionar y de estudiar obras y autores, sectorizándolos, ubicándolos por lenguas y por épocas y es, todavía hoy, la modalidad de trabajo con que se ejerce en la universidad. Hemos estado disecando la literatura; oponiéndose a la imagen multifacética que Borges defiende en sus textos, aunque sabemos que las obras que dan lugar a un canon de una literatura nacional, tienen una finalidad primera, integran un biblioteca normativa que acompaña la construcción, como en el caso de América, de cada Estado nación. Hay, en esta opción, algo de obsoleto; ambas instituciones, la Nación y la Biblioteca son construcciones fraguadas en el siglo XIX, después de las Independencias que si bien han ido variando con el tiempo y se han ido transformando, algunas de manera radical, están en conflicto en estas últimas décadas frente a la fuerza que han tomado los grandes conglomerados establecidos sobre todo con fines económicos y financieros. Como lo explica Lelia Area en su ensayo Una biblioteca para leer la Nación,* la Biblioteca fraguada en el siglo XIX imprime una orientación de lectura que, como en el caso de la nación argentina, teje un discurso ideológico, político que va desde los escritos fundadores de Sarmiento y otros escritores de su tiempo, que se levantan contra el dictador Rosas, hasta el presente, para ubicar dos figuras contrapuestas, la del dictador (como faccioso) y la de sus antagonistas liberales defensores de un modelo de Patria europeizado. La Biblioteca de cada nación, dice Lelia Area, se concibe como un territorio imaginario que da cabida a una construcción ideológica "diseñada por un sujeto social que traspone en ella sus intereses y también enmascara sus contradicciones".* Apoyándose en la metáfora de Jorge Luis Borges de "La biblioteca de Babel", Lelia Area forja un concepto operatorio que sirve de figura de lectura y clave de referencia a todo corpus de literatura nacional, producto de contradicciones, resultado de un conflicto que enfrenta "voces airadas y antitéticas" pero que finalmente se admite como totalidad. En todo catálogo de lo nacional se leen "versiones" y no sólo "visiones" que corresponden a una determinada "necesidad histórica", a una dirección que resulta de un análisis reductivo (teleológica) compuesto de voces que pueden 
ser disonantes, ya que selecciona escritores o autores en función de un proyecto político nacional que se alimenta en cada época. ${ }^{5}$

\section{De la Biblioteca nacional a la estética relacional}

Me propongo contribuir con este trabajo a una revisión crítica de la literatura que se instala hoy más allá de las Bibliotecas que corresponden a cada nación. El contexto de globalización de estos últimos ańos permite establecer un cuestionamiento de ese "orden" literario en gran parte por las formas de actuar y de expresarse del escritor contemporáneo y por las maneras que tenemos de leer la literatura (a través de diferentes canales de información, y en recepciones simultaneas pero no necesariamente conectadas, en varios lugares al mismo tiempo y en diferentes lenguas). Sin embargo, Nicolas Bourriaud reconoce rasgos comunes a esta comunidad de artistas que se mueven a nivel internacional y para describirlos forja el concepto de Radicante. ${ }^{*}$ Consuma así su teoría sobre el arte contemporáneo como lugar múltiple y relacional, compuesto en cada obra por el aporte de diferentes terruños, por obras alimentadas por las diferentes "raíces" adoptadas por cada autor. Su experiencia internacional lo guía; N. Bourriaud, antes de dirigir la Tate Modern Gallery de Londres, recorrió el mundo ("París, Venecia, Kiev, Madrid, La Habana, Nueva York, Moscú, Turín; Londres por último", dice en su Prólogo) y su experiencia por esos diferentes lugares así como el encuentro con artistas de diferentes latitudes lo llevaron a reflexionar sobre el arte actual como modo relacional y la experiencia crítica como reflexión y práctica que nace de una "vida nómada". Las interrogaciones de Bourriaud en este ensayo se centran en preocupaciones que son comunes a otros críticos que trabajan sobre el multiculturalismo, la globalización cultural. Pero la

\footnotetext{
${ }^{5} \mathrm{He}$ analizado estos aspectos en relación con el canon que compone el corpus de la llamada "Literatura uruguaya" en los trabajos siguientes: "Darwin, ¡escritor uruguayo? Reflexiones sobre territorios literarios en devenir" (Nuestra América. Revista de Estudios sobre la Cultura latinoamericana $N^{\circ}$ 6. Cultura Uruguaya. Coord. Francisca Noguerol. Edições Universidade Fernando Pessoa, Porto, agostodezembro 2008, pp. 115-139), “¿Por qué raros? Reflexiones sobre territorios literarios en devenir” (Raros Uruguayos Valentina Litvan - Javier Uriarte (Coord.), Revista LI.RI.CO (Literaturas Rioplatences Contemporáneas) № 5. U. Paris 8, 2011, pp. 29-53.) y "Especulaciones. Uruguay en territorios literarios en devenir. Por una cartografía abierta de lo nacional /americano en literatura" (Palabras sitiadas. Revista de la Biblioteca Nacional No 6/7 2012 pp.87-103. Coord. Ana Inés Larre Borges, Directora de la Revista).
}

* (BOURRIAUD, Nicolas Radicante. Michèle Guillemont (trad.). Adriana $\mathrm{Hi}$ dalgo: Buenos Aires, 2009.) 
pregunta que conduce este trabajo teórico sobre radicantes es interesante: “'por qué se ha comentado tanto la globalización desde un punto de vista sociológico, político, económico y casi nunca desde una perspectiva estética? ¿Cómo afecta el fenómeno de la mundialización a la vida de las formas?"

"Radicante" es, como los rizomas de Gilles Deleuze y Félix Guattari en Mille plateaux (1980), una metáfora que se basa en una noción de la biología. Para Bourriaud designa tanto la movilidad del artista (movilidad espacial: exilios y todo tipo de desplazamiento, como imaginada a través de contactos librescos o "on line"). Tanto una como la otra dejan huellas o trazados en la obra que emergen de "suelos" recorridos realmente o por el imaginario del autor y que la obra convoca. Los artistas radicantes, como la fresa o la hiedra, se alimentan a medida que se extienden por diferentes suelos y gracias a la facultad de desarrollar nuevas raíces. De esta manera la primera raíz, que correspondería metafóricamente al país de origen es tan importante como la ultima raicilla; todas juntas designan un organismo o composición en movimiento que se nutren a medida que van extendiéndose por los terrenos en los que habita o habitó el artista o que habitan las obras. Este mecanismo, traspuesto a la obra de arte, significa que se elabora en presencia y con la participación de diferentes influencias. Inspirándose en las lecturas de Walter Benjamin y Georges Bataille, a quienes Bourriaud toma como mentores en la manera de exponer ("un tema por jirones, una escritura fragmentaria y vagabunda”), él opta por un tipo de crítica que no acepta los desarrollos rectilíneos, que se asemeja a lo que él llama una "presentation powerpoint. una imagen, una orientación”. Esta modalidad permite la construcción de "un archipiélago conceptual" que pone el acento en la imagen en movimiento de todo proceso de creación. Mi propósito es transferir la modalidad crítica que Bourriaud aplica a las artes plásticas y a los artistas plásticos del presente, a la producción literaria y al recorrido que los escritores adoptan para relacionarse directa o indirectamente con lo Otro o los otros. La opción de ir a recabar en la lectura distintos elementos que se vuelcan en la rescritura es una práctica conocida que se ejercita como lectura y traducción del otro y de lo otro que encierra cada texto. Pero Bourriaud explica cómo ha llegado a la metáfora radicante como proyecto de obras que se adentran y se nutren de "arraigos sucesivos y simultáneos": 
En vez de oponer una raíz a otra, un "origen" mitificado a un "suelo" que integra y uniformiza, ¿̨no resultaría más ingenioso recurrir a otras categorías de pensamiento que nos sugiere un imaginario mundial en plena mutación? [...] Hablemos de botánica. Al organizar las condiciones materiales del movimiento, el mundo contemporáneo facilita nuestras transplantaciones... ¿¿Fue una casualidad si el modernismo elogió, desde su inicio hasta su fin, la raíz? Fue radical... ¿Y si la cultura del siglo XXI se inventara con esas obras cuyo proyecto es borrar su origen para favorecer una multiplicidad de arraigos simultáneos o sucesivos?*

Los estudios culturales y postcoloniales han jugado un rol importante en este cambio de perspectivas del análisis literario. Sin embargo, han sido relevados por este modelo crítico que tiene en cuenta la relación, la comunicación o el diálogo constante que se mantiene (sobre todo en el marco de la sociedad hiperglobalizada), y se amplifica con los intercambios "simultáneos o sucesivos" que se consiguen vía las nuevas tecnologías de la información internet (la pantalla que da acceso a lo múltiple en uno).

Propongo, siguiendo a Bourriaud, que este modelo del radicante se extienda al sujeto crítico de la literatura; éste también practica el desplazamiento real o imaginario (modo "internet") que facilita el acceso a fuentes bibliográficas, consultas de textos y que ha dado lugar a un cambio en la recepción de los autores y de sus producciones. Así, y luego de haber cuestionado la perspectiva crítica que se basa en el canon con que se construyen "Biblioteca" por nación o por continentes, trataré de ilustrar con ejemplos lo que podría ser otro tipo de Biblioteca (babélica, rizómica, radicante), concepción que implica un cambio de perspectiva crítica que subraye la relación, los constantes pasajes, más allá de fronteras políticas o culturales, los desplazamientos reales o imaginarios tanto como los residuos y trazas que ilustran en un discurso la inclusión visible o invisible de un autor en otro, de una modalidad de escritura o un motivo o una figura del discurso en otro discurso. No se trata ya de encontrar apoyo, como lo hacen los estudios culturales, en la noción de "lugar" de la escritura, el desde donde se escribe parece obsoleto, sino que se trata de analizar la significación de relación que tienen los territorios reales o imaginarios que recorre

\footnotetext{
${ }^{6}$ Utilizo el término Biblioteca en los dos sentidos dados antes, ambos metafóricos: el que forja Lelia Area, para aludir a la construcción de un patrimonio cultural de obras que acompañan la construcción de construir una nación y con el sentido que le da Jorge Luis Borges, como acervo patrimonial de la humanidad.
}

* (BOURRIAUD, Nicolas. Radicante, op. cit.: 22.) 
* (BRANDO, Oscar. Intervención en el Séminaire Les Amériques - dirección N. GlRALDI DEI CAS- 4/05/2012, Université Lille 3.): toda escritura. Todo escritor escribe sous la contrainte, dice Oscar Brando ${ }^{7}$, de la lengua y de una tradición por la que él opta, y que puede tener la dimensión de lo local o la magnitud de lo universal:*

Estos escritores radicantes que dialogan en sus prácticas literarias con diferentes culturas, escriben en el entredós de diferentes lenguas indican la emergencia de nuevos paradigmas literarios y dan lugar a pensar en nuevas cartografías literarias. La lectura de los mismos nos permite comprobar que hay huellas, residuos que componen gramas o gramáticas diferentes, relacionadas, al mismo tiempo, a distintos patrimonios y tradiciones culturales, que prueban la caída de la máscara con que se identifican las naciones, el cuestionamiento de la "unidad cultural", idea con la que se forja el imaginario nacional, incluso cuando ésta surge del conflicto del mestizaje no siempre reconocido y asumido como tal.

Para emprender esta reflexión sobre el devenir de la literatura más allá de fronteras nacionales, para leerla a partir de las relaciones que ella misma establece, de los intercambios que pauta, haciendo de ella un territorio dialéctico, he adoptado nociones claves de la sociología relacional, ${ }^{8}$ en primer término porque admite, como en toda comunidad o sociedad, que haya emergencia de configuraciones siempre variables, no preestablecidas. Estos lazos sitúan la literatura como sistema que pauta la historicidad de los fenómenos que contiene en las diversas expresiones que la componen pero no determinan de antemano la finalidad de los mismos. La literatura enseñada desde esta perspectiva, que se reseñe o se analice con estas bases, no se reduciría al análisis de la obra de algunos autores que se acomodan dentro de una categoría o catálogo construido por y para cada nación (la literatura "nacional" en relación con una lengua), ni a catálogos de ventas de las editoriales que ponen etiquetas a los autores para formatearlos según el gusto también formateado de los lectores, sino que buscaría los rasgos de una "estética de lo relacional” (Nicolas Bourriaud) y se interesaría a la manera que tienen ciertos artistas de hacer compartir y comunicar, aunque sean muy diferentes entre sí, los objetos que producen.

\footnotetext{
${ }^{7}$ Oscar Brando es miembro del equipo de Lille y de la red NEOS NEWS (NortesEstes-Oestes-Sures-Américas) que está trabajando sobre figuras y trayectorias de escritores radicantes y sobre la noción de un espacio literario global que nutre cada escritor.

${ }^{8}$ Como síntesis y aproximación a los principios de la sociología relacional, Cf. Claude Vautier, "La longue marche de la sociologie relationnelle" (op. cit.: 77-106).
} 
Según Bourriaud,* con esta noción - esthétique relationnelle - se define una serie de prácticas artísticas que emergen simultáneamente, a fines del siglo XX, en varias partes del mundo. Como comisario de exposiciones, $\mathrm{N}$. Bourriaud nota la aparición de diversas modalidades o prácticas artísticas que contribuyen a la emergencia de situaciones relacionales nuevas en cada sociedad, que muestran una cierta resistencia al formateo social:

D'où proviennent les malentendus qui entourent l'art des années quatre-vingt-dix, sinon d'un déficit du discours théorique? Critiques et philosophes, dans leur écrasante majorité, répugnent à prendre à bras le corps les pratiques contemporaines : celles-ci demeurent donc, pour l'essentiel, illisibles, car on ne peut percevoir leur originalité et leur pertinence en les analysant à partir de problèmes résolus ou laissés en suspens par les générations précédentes. Il faut accepter le fait, ô combien douloureux, que certaines questions ne se posent plus - et par extension, repérer celles que se posent aujourd'hui les artistes : quels sont les enjeux réels de l'art contemporain, ses rapports à la société, à l'histoire, à la culture? La première tâche du critique consiste à reconstituer le jeu complexe des problèmes qui se dressent à une époque particulière, et à examiner les réponses diverses qui leur sont données. ... Comment décoder ces productions apparemment insaisissables, qu' elles soient processuelles ou comportementales - en tous cas " éclatées ", selon les standards traditionnels - en cessant de s'abriter derrière l'histoire de l'art des années soixante? Citons quelques exemples de ces activités : Rirkrit Tiravanija organise un dîner chez un collectionneur, et lui laisse le matériel nécessaire à la préparation d'une soupe thaï. Philippe Parreno invite des gens à pratiquer leurs hobbies favoris le jour du premier mai, sur une chaîne de montage d'usine...*

Bourriaud se centra en el análisis de la actividad artística actual en relación con las características de esta sociedad globalizada. Su concepto de estética relacional implica ante todo un estudio del contexto, para destacar, luego, la importancia de correspondencias, de asociaciones que pueden parecer absurdas, pero que son signos de una sociedad diseminada y que, al mismo tiempo, se manifiesta en prácticas semejantes de uno al otro lado del planeta. Nos interesa extender el concepto de estética relacional al de crítica relacional para definir una postura crítica más dinámica y menos doctrinaria con respecto al fenómeno literario y, por otro lado, para leer e interpretar lo que está vinculado a la vida o a la obra de un escritor como resultante de una actividad relacional (es decir social) que no se detiene solamente en la obra sino que también se preocupa
* (BOURRIAUD, Nicolas. L'esthétique relationnelle. Dijon: Édition Les presses du réel, 1998.) 
* (BERTI, Eduardo y COZARINSKY, Edgardo. Galaxia Borges. Buenos Aires: Adriana Hidalgo, 2007.)

* (BORGES, Jorge Luis. Kafka y sus precursores. In: Otras inquisiciones. Obras Completas. Buenos Aires: Emecé, 1996, t. 2: 88-90.) por los lazos que ésta crea, por las correspondencias que establece con todo tipo de prácticas y fenómenos, tanto de su época como de las anteriores. Se trata de volver a subrayar la historicidad de la literatura y su extensión en forma de continuum; cómo, analizando diferentes obras de diferentes épocas, se encuentran huellas a las que quizás no se les prestó atención que permiten, una vez percibidas, sentar relaciones inesperadas. Esta postura se detiene y da importancia a huellas y residuos, pero también a los pasos, contactos, bifurcaciones que construyen en la lectura ese continuum, dando a leer diferentes tipos de precursores. A la manera de Borges, pre-cursores, es decir, autores que pautan un recorrido, la línea que va de uno a otro texto, o de uno a otro autor. Pero estos precursores no se han fabricado con antelación ni se leen según un plan preestablecido; si generan nuevas "constelaciones de escritores" y desplazan las cartografías literarias conocidas es porque leen de una manera diferente los textos dando lugar a nuevas e inesperadas correspondencias. En lugar de encerrarse en bibliotecas que contienen el patrimonio reconocido por una comunidad nacional, proponen varias aristas que deberían ocupar nuevos anaqueles de la Biblioteca, que permitan ubicar a escritores olvidados o a un mismo autor en varios anaqueles de Bibliotecas diferentes. Un mismo escritor puede formar parte del patrimonio de varias naciones, este tipo de reivindicación se practica en general en el caso de celebridades que a menudo se integran en dos parnasos nacionales (es el ejemplo de Jules Laforgue, le Comte de Lautréamont et Jules Supervielle, poetas considerados tanto franceses como uruguayos).

Nuestra propuesta tiene sus antecedentes: Eduardo Berti y Edgardo Cozarinsky* han fabricado Antologías en las que integran escritores de distintas épocas; al leer el conjunto de esos relatos como un todo surgen nuevos sentidos que no están necesariamente contenidos en uno o varios de los cuentos recogidos. El todo difiere de las partes, es lo emergente, un plus de sentido ausente de los cuentos (partes) y que, sin embargo las representa. Estas constelaciones o galaxias de cuentistas y de obras se forman por afinidades que encuentran los lectores (en este caso, los dos autores de la antología), que agrupan autores en torno a un "precursor". El antecedente de esta manera de ver la literatura está en el ensayo "Kafka y sus precursores" de JL Borges.* Borges sigue el rastro de diferentes voces, tonos, temas que llevan desde otros textos a los del autor de "La metamorfosis". Borges denomina "piezas heterogéneas" a estos 
componentes de un conjunto de obras que no se definen en principio como "partes" que componen la obra de Kafka: la paradoja de Zenón, un apólogo de Han Yu, prosista del siglo XX, los escritos de Kierkegard, una de las Histoires désobligeantes de Léon Bloy... son esas "piezas heterogéneas" muy distintas y distantes entre sí, pero: en cada uno de esos textos está la idiosincrasia de Kafka, en grado mayor o menor, pero si Kafka no hubiera escrito, no lo percibiríamos; vale decir, no existiría [...] El hecho es que cada escritor crea a sus precursores. Su labor modifica nuestra concepción del pasado, como ha de modificar el futuro. En esta correlación nada importa la identidad o la pluralidad de los hombres...*

Para que la figura del precursor emerja, el lector (Borges con respecto a Kafka y, más tarde, Berti y Cozarinsky con respecto a la Galaxia Borges que ellos construyen), trabaja en correspondencia con el escritor, inicia una relación que se concretiza en la lectura, que da lugar a una figura especular (un autor, una modalidad de escritura se descubre en el espejo de otro). Por eso, "galaxia" corresponde, en el vocabulario de Berti y Cozarinsky, a una labor de mediación intelectual que puede tomar diferentes formas, "una suerte de telarańa que une a diferentes escritores que supieron cumplir roles de lo más variados: maestros o discípulos, rivales o cómplices, interlocutores varios, colaboradores cercanos, coautores ocasionales, etc.".* Se trata de un desplazamiento de sentidos, como en la teoría de la traza, de la trama, de la grama, que Derrida analiza con la noción de diseminación* y que caracteriza la literatura, así como su capacidad de decir o relatar sobre todos los saberes.

Territorios literarios en devenir

Esta postura crítica abre acceso también a la relación con otros tipos de fenómenos y realizaciones artísticas que están en diálogo constante con la literatura, en particular la Historia y las otras artes (cine, plástica, música) que representan, con otras modalidades, relatos, como la literatura, que expresan, discurren y examinan memorias, archivos, testimonios que reviven lo que está sucediendo en diferentes territorios a lo largo de los siglos así como los traumas, las divisiones políticas, los conflictos y la barbarie social.

La noción de territorio que tomamos de G. Deleuze y F. Guattari, ${ }^{9}$ no se asimila simplemente a una toponimia o definición de

${ }^{9}$ Cf. DELEUZE, G. e GUATTARI, F. Capitalisme et schizophrénie t.1: L'anti
* (Ibidem : 89-90.)

* (BERTI, Eduardo y COZARINSKY, Edgardo. Prólogo. In: Galaxia Borges, op. cit.: 6.)

* (DERRIDA, Jacques. La dissemination. Paris: Seuil, 1972.) 
un lugar geográfico. Todo trazado territorial distribuye las relaciones de un afuera y un adentro, tanto en el caso del sujeto como en el de identidades colectivas. Es un lugar de ajustes y de negociaciones así como de redistribución de competencias. Consideramos esta noción de territorio esencial para nuestro trabajo asimilada a un espacio de negociación y de redistribución, de transferencias múltiples que, en el caso de la literatura, es interesante relacionarlo con la cuestión de la intertextualidad. Por eso, otra de las claves de lectura en este trabajo es la noción de pasajes que aporta el pensamiento de Walter Benjamin; pasajes que permiten presentar, en movimiento y en negociación entre diferentes territorios y diferentes tipos de relaciones. La literatura de una época, por ejemplo, la literatura relacionada con Uruguay (que correspondería a mi especialidad), no solamente como nación y lugar geográfico, primer espejo de identidad para algunos escritores, sino como territorio que asocia discursos y escenas literarias en relación con cuestiones y contextos diferentes, de adentro y de afuera de "lo uruguayo". Pasajes, por ejemplo, para leer el entredós, entre dos épocas, entre dos territorios que es motivo de escritura en diferentes autores, pasajes también que describen desterritorializaciones y reterritorializaciones. Trataré de mostrar que hay un vaivén que deja huellas y, al mismo tiempo, manifiesta distancias que dan a conocer la traductibilidad de contenidos y sentidos por medio de las palabras, así como el acercamiento más o menos marcado a una circunstancia, a un tema o a un motivo.

Yo tomaré, para terminar, un ejemplo de "diseminación " de territorios literarios que asocio sin ambages a la llamada comúnmente "literatura uruguaya". Este ejemplo se presenta como "descentralizado" por diferentes razones: se trata de Darwin, un científico de lengua inglesa que se vuelve escritor cuando empieza a escribir su Diario en el Beagle, un científico que no tiene vocación de dar a conocer una obra literaria ni, tampoco, una teoría científica. Y sin embargo, Charles Darwin, según la crítica relacional, sería un "precursor" de Félix de Azara, ${ }^{10}$ a quien leyó y cita varias

Edipe (Ed de Minuit, 1973), et t.2 Mille plateaux (Ed. de Minuit, 1980).

${ }^{10}$ Félix de Azara (1742-1821), militar, ingeniero, explorador, cartógrafo, antropólogo, humanista y naturalista al servicio de la Corona de España, es el autor de una obra monumental de relevamiento de la frontera entre los dos Imperios. Espańa y Portugal, por el tratado de San Ildefonso (1777), fijaban las fronteras de sus posesiones en América del Sur. Se eligió a Azara para formar parte de los comisarios encargados de delimitar con precisión las fronteras españolas. Parte 
veces, cuando le toca hacer observaciones sobre los territorios limítrofes entre el Imperio portugués del Brasil y la "Banda Oriental" del Río de la Plata, y el uruguayo Tomás de Mattos podría ser su "precursor” cuando escribe ¡Bernabé, Bernabé! (1988).

Varios conocimientos y muchos sentidos se tejen en el Diario de Darwin, escritor que puede ser interesante integrar en un seminario de literatura latinoamericana para analizar cómo emerge algo que concierne una nueva mirada a lo nacional en otros territorios, con otras lenguas y adosado a un proyecto científico. El célebre naturalista inglés tenía apenas 27 años de edad cuando, en 1832, se enrola en la hoy famosa expedición del Beagle. Escribe en su lengua para dar testimonio de lo que va descubriendo a medida que recorre América del Sur. La teoría o lo que llegará a llamarse su teoría se sostiene por el pilar de la observación y se apoya en el trabajo hecho por otros naturalistas, como Félix de Azara, que había estado antes que él en América. Darwin tiene la formación de un naturalista de su época: describe lo que ve, lo localiza, lo dibuja, lo compara con lo que otros han descubierto y han descrito antes que él, y va coleccionando todo lo que encuentra. Pocos lo han leído, son famosas sus descripciones sobre las tortugas gigantes de las Galápagos, pero a mí me llamó la atención las descripciones que hace de la región del Sur, de los animales vivos o fosilizados que estudia en esos lugares y se sorprende cuando los observa, lo que hace que se detenga en detalles (diríamos nosotros, los profanos). Una serie de observaciones, de animales, huesos y fósiles durante su travesía por Sudamérica van a predisponer a Darwin a que acepte la mutabilidad de las especies, así como su ocasional extinción. ${ }^{11}$ Le interesan la relación entre las especies fósiles y los organismos vivos presentes en el mismo lugar, así como las particularidades de los que encuentra en ese continente, por el hecho de que había permanecido aislado durante milenios. Pero se interesa mucho también en los habitantes. Cabe destacar lo sensible de su observación cuando recorre, durante más de un año, las tierras que bordean el Río de

hacia Sudamérica en 1781 para una misión de algunos meses y se quedará durante 20 años. Según su testimonio, se dirigió a Asunción, Paraguay, para realizar los preparativos necesarios y esperar al comisario portugués. Dada la tardanza del comisario portugués, Azara decidió emprender un viaje por su cuenta y realizar un mapa de la región. (Consulta en Wikipedia: 15-02-2013.)

${ }^{11}$ Cf. Edna SUÁREZ, Edna. Darwin en sociedad. In: Ana Barahona, Edna Suárez, Sergio Martínez (comp.) Filosofia e historia de la biología. México: UNAM, 2004, cap. 6, pp. 169-174. 
* (DARWIN, Charles R. 1839: III: 44-72. In: Narrative of the surveying voyages of His Majesty's Ships Adventure and Beagle between the years 1826 and 1836, describing their examination of the southern shores of South America, and the Beagle's circumnavigation of the globe. Journal and remarks. 1832-1836. (1839). Revision and Scanned and OCRed by John van Wyhe 2.2005; proofread and corrected by Sue Asscher 3.2006. RN3. (c) 2002-9 The Complete Work of Charles Darwin Online. John van Wyhe Director. Consultado: 4-2-09.) la Plata. Relata el episodio de su llegada al puerto de Montevideo pero se detiene aun con mayores detalles en la ciudad de Maldonado, los campos y las sierras de Minas. Da la impresión, cuando se lee esta parte de la crónica de su viaje, que fue ayer que se tomó esa instantánea que queda impresa en la descripción que hace Darwin de esos territorios. El se detiene en la figura de algunos propietarios de estancia y de gauchos que observa con sentimiento de extrańeza y los describe con mucho esmero y una chispa de humor.* Pero Darwin también se siente observado, se ve en el otro y actúa en el entre-dos del encuentro que está hecho, sobre todo, de impresiones y en base a un mutuo descubrimiento. Este se produce en un estar frente a frente pero desfasados, lo que permite al lector del Diario, y desde la perspectiva histórica que es la nuestra, captar diferencias. Por ejemplo, Darwin interpreta cómo lo ven los otros, qué piensan de él los gauchos cuando se lava las manos frecuentemente. Utiliza en el Diario la palabra abluciones, "me ven a menudo haciéndome abluciones" y, a partir de esta observación, interpreta cómo lo perciben los otros, e imagina y se figura que lo ven como "si fuera un musulmán”. Figurándose así, en el espejo de la mirada invertida, en la mirada del otro que él refracta y asume en su Diario, Darwin se nos muestra lejano y extrańado en la otra faz del mundo que representa para él esa otra cultura (la americana), lo que lo lleva a la conclusión de que lo asimilan a un oriental-musulmán. Pero tenemos derecho en preguntarnos qué sabrían aquellos gauchos uruguayos de la cultura musulmana y de la práctica de las abluciones. Las observaciones y descripciones que Darwin hace de esos territorios, entre pampa y sierra, al pasar de Argentina a Uruguay y al Brasil, se someten también a la comparación de lo que explican las teorías u observaciones contenidas en los libros que forman parte de su biblioteca personal, de médico y naturalista (Lamarck, Malthus, Grant... Félix de Azara...). Esos libros lo acompañan durante su viaje y, más tarde, componen con él, en su gabinete, las meditaciones que, durante más de 20 años, el resto de su vida, lo llevan a concebir lo que será la teoría de la evolución, una de las pocas teorías científicas que no se somete a los tests experimentales para poder refutarla (hoy día sí, en parte, se pueden probar ciertas hipótesis de la teoría de la evolución). Darwin siguió escribiendo sobre lo que se llamó más tarde la selección natural y la perduración o duración de algo, de ciertos rasgos comunes entre todas las especies. Los pájaros (ñandúes), marsupiales (comadrejas) y roedores 
que él describe lo impresionaron tanto como la geología, la geografía y los fósiles y huesos que encuentra porque tienen eso, ese algo que lo intriga y que lo lleva recorrer con incesante curiosidad esas tierras lejanas. Tanto le apasionan y le interesan que cuenta en su Diario* $^{*}$ cómo llegó a comprar un cráneo a un gaucho de Maldonado para poder llevárselo y compararlo con otros cráneos encontrados en otras latitudes.

Darwin se basa en las notas y descripciones de Félix de Azara sobre los territorios de las Provincias del Rio de la Plata que lindan con el Brasil en particular la "Banda Oriental", nombre que Darwin utiliza todavía para designar esos territorios en las páginas de su Diario (quizás por influencia de Azara), aunque recoge eventos sucedidos después de 1830 , es decir, cuando Uruguay ya es un país independiente. Siguen intrigando a sus lectores porque son testimonios de algo, de una inquietante extrañeza que perdura y que se agudizó en los momentos de la última dictadura (19731983). Pensamos que siendo singulares, corresponden también al conjunto de las culturas del Sur y que, como las Cielitos de Bartolomé Hidalgo, deberían servir para componer una "constelación" que se someta a la lectura de una crítica de lo relacional que permita presentar un panorama de la producción literaria que comprenda referencias a diferentes territorios y fronteras fluctuantes de esa región. El crítico debería abordarlos en su interrelación con una historia cultural común, entretejida por pasajes constantes entre Argentina, Brasil, Uruguay, Paraguay. Jorge Luis Borges también sitúa en esos territorios fronterizos muchos de sus cuentos, como clave de la Historia que debería contarse desde la perspectiva de puntos de vista contradictorios o contrastados. Con su particular manera de narrar, sin tener en cuenta las fronteras culturales y practicando las travesías y bifurcaciones, haciendo suyo, como argentino, el patrimonio universal, interpreta manchas y cicatrices que son comunes, mejor dicho, que se identifican, al leer sus relatos, como posibles manchas, cicatrices que marcan tanto una persona como la Historia. A veces se trata de partículas minúsculas que revelan errores monstruosos, que pueden extenderse, por su significación, a lo que sucede en otras latitudes y culturas. Así sucede con el personaje del relato "La forma de la espada" (Ficciones, 1944). La cicatriz con que se identifica al traidor es, en realidad, la marca que lleva en la cara el relator del cuento, el Inglés de la estancia La Colorada, quien se confiesa a Borges, autor y recep- 
* (BRANDO, Oscar "La narrativa uruguaya y sus fantasmas (1985-1997)". Revista papeles de montevideo, $\mathrm{N}^{\circ}$ 2, Montvideo, Trilce, 1997: 10-33.).

* (CHANTRAINE-BRAILLON, Cécile. Leyenda y mito en ¡Bernabé Bernabé! de Tomás de Mattos. In: Mémoire de Maitrise. Dirección Annick Louis, Université de Reims, 1999.). tor del cuento. Borges, en el lugar del confesor es también la figura del lector en el cuento que recupera, como dos caras de una misma moneda, al traidor y al héroe en una sola persona. Lo interesante también es el territorio en el que se refugian estos personajes, esas tierras de nadie, fronteras perdidas, olvidadas hasta muy entrado el siglo XX. La escena del cuento, el diálogo o confesión de Borges con el Inglés de la Colorada, se sitúa en la región entre Tacuarembó y Rio Grande do Sul. Ese territorio fronterizo evoca otros que cargan con un destino similar y que han entrado a la Historia literaria con su dosis de olvidos y miserias. Por ejemplo, Misiones en Los Desterrados de Horacio Quiroga, territorio que sigue abonando la literatura y es lugar de predilección para situar grandes intrigas basadas en olvidos prominentes de la Historia oficial tanto argentina, como paraguaya, como uruguaya. La frontera regional, cultural, de género se representa también en la novela ;Bernabé, Bernabé! (1988) de Tomás de Mattos; de esa región de Tacuarembó viene la protagonista, Josefina Peguy, conciencia lectora de archivos olvidados y actora de los "descubrimientos" que revela la novela. Estos movimientos dobles o triples revelan una urgencia en la escritura, la revelación por la escritura de algo que ha permanecido oculto, no enunciado, así como la rebelión de una mujer en la escritura, lo que mantiene en vilo al lector de la novela epistolar ¡Bernabé Bernabé!. Esta novela fue escrita con el propósito de desbaratar los prejuicios de la univocidad y de los silencios de la voz de la Historia, en los años posteriores a la dictadura uruguaya. $\mathrm{Al}$ desarrollar una reflexión a propósito del gran debate sobre la fractura de la identidad uruguaya marcada por olvidos significativos, la novela de Tomás de Mattos cumplió con la función de ensayo* La novela se construye también como una tragedia clásica, según Cécile Chantraine-Braillon.* El autor elige, en efecto, que la voz del narrador de hechos históricos comporte la heterodoxia de ser una mujer y se centre en un episodio deliberadamente olvidado, silenciado por la Historia nacional que se relaciona con la exterminación de los Charrúas (episodios de 1831 en adelante, justamente en momentos en que Darwin está en la región del Río de la Plata). Este pecado original de la joven República, ficcionalizado por Tomás de Mattos, es la clave de entrada de la novela y, como dice Rosario Peyrou (1998), la clave de su éxito: la novela provocó polémicas públicas, fue discutida hasta en el Parlamento nacional y iBernabé, Bernabé! "significó para de Mattos la ruptura del estrecho círculo 
de lectores habituales de literatura uruguaya. La novela lleva vendidos veinte mil ejemplares en un país donde las tiradas habituales no suelen pasar de mil, arrasó con todos los premios nacionales: el Bartolomé Hidalgo de la crítica, el de la Intendencia Municipal de Montevideo, el del Ministerio de Cultura y el de la B'nai B'rith".*

Pero la novela de Tomás de Mattos no suscita nuestro interés solamente por lo que denuncia con respecto a ese hecho ocultado por la historiografía nacional, sino por su reflexión poética con respecto a la violencia del poder y sus trampas, entre otras por los discursos y la propaganda ideológica que los sustenta, por lo que, la obra de de Mattos se puede leer en concordancia con autores muy diferentes que han puesto en evidencia los horrores de la guerra, como Charles Peguy (autor de predilección de T. de Mattos, por ser una bisagra entre su cristianismo militante, su fe socialista y su acción en defensa de Dreyfus), la hipocresía reinante, como lo hace Céline con sus denuncias, aunque se base en sus convicciones racistas, con respecto a los horrores de la guerra y a la discriminación racial, la presencia del fascismo en América latina, como lo hace Roberto Bolaño, con respecto a la exterminación política en el contexto de varias dictaduras.

Tomás de Mattos publica una nueva versión de su novela diez años más tarde basándose en nuevas investigaciones efectuadas por el historiador Eduardo Acosta y Lara que ponen en evidencia la premeditación de la masacre cometida según un plan del gobierno uruguayo de la época, dirigido por Fructuoso Rivera, primer presidente de la nación uruguaya independiente. Este acto de barbarie fue perpetrado por el primer presidente uruguayo y contó con la participación del General argentino Juan Lavalle y un regimiento de soldados brasileños. El complot contra los Charrúas puede leerse, entonces, como una prefiguración de la terrible guerra de la Triple Alianza contra el Paraguay e, incluso, como precursor del monstruoso Plan Cóndor.

En la novela, como en el caso del pasaje del Diario de Darwin que explicamos antes, la expresión juega con lo especulativo, entre lo personal (epístolas de Josefina Peguy a su amigo periodista) y la importancia exterior que puede tener la intriga (avance para la ciencia en el caso de Darwin, conocimiento de una parte ocultada de la Historia para el Uruguay que quiere saber la verdad de lo que pasó, representado en la novela por el personaje femenino de Josefina Peguy). Ambos conocimientos han quedado en vilo, sin
* (PEYROU, Rosario, El País Cultural No. 144, Montevideo, viernes 7 de agosto de 1992:5) 
resolverse. En el caso de Darwin, es necesario llegar al siglo XX para que, con los métodos de la genética, sus hipótesis sobre la evolución de las especies y la similitud asombrosa que puede haber entre ellas, a pesar de haber vivido alejadas en el espacio y en el tiempo, sean leídas en las trazas que deja en su obra. Los nuevos paradigmas científicos se refieren a sugerencias y observaciones de Darwin por lo que ha puesto en evidencia el "texto genético" (ADN, genes del desarrollo, genes domésticos, genes de regulación). Este discurso de la genética dialoga, a distancia, con las sugerencias y reflexiones que aparecen en el discurso de Darwin. El caso "Darwin" permite analizar toda la carga de mitificación y de ideología que existe en torno a los descubrimientos, no solamente científicos sino también los que emergen en literatura, y la rapidez con la que, en algunos casos, se procede a su canonización. Al leer el Diario de Darwin descubrimos que sus hipótesis de trabajo sobre lo que él llamo la "transmutación" de las especies fueron madurando a medida que analizaba los fósiles y animales vivos que recoge en América. El caso "Darwin" nos muestra también cómo nos comportarnos apasionadamente frente al objeto de estudio y cómo el deseo de saber más nos guía a medida que vamos elaborándolo, se instala en nosotros como discurso de una verdad que se quiere compartir y por eso se escribe. Por eso comparamos el discurso de Darwin, hecho de observaciones pertinentes y lecturas desprejuiciadas sobre una realidad nueva para él, a la de otros escritores y a la representación que se hace de ellos en la figura de Josefina Peguy que lee de manera diferente, desde otro ángulo, los materiales del archivo de su marido que contienen elementos importantes para comprender la Historia nacional. La construcción de ;Bernabé Bernabé! de Tomás de Mattos revela el valor de la mirada y la función de la lectura (que corresponde con el lugar central que ocupa la observación en el método científico). Josefina, desde otro lugar del decir con respecto al que ocupaba su marido en la sociedad de su época, permite reflexionar y encontrar una sutil différance (término que tomamos con la trasmutación que forja Derrida: différence en la pronunciación se desliza y se confunde con la misma palabra si fuera escrita con una $a$ antes de la nasal: différance). Su interpretación de los archivos familiares representa una manera nueva de representar las relaciones del sujeto con la historia y la sociedad de su tiempo para descubrir, desde otro lugar, los nudos de un ocultamiento practicado por la Historia para justificar el presente. Al 
elegir la figura de Josefina Peguy, una mujer viuda que declara en la novela ser contemporánea de Darwin, aunque más joven que él (su padre era amigo de Bonpland, naturalista francés, relacionado con la expedición de Darwin en Río de la Plata), Tomás de Mattos revela algo más, una huella, la différance con que se pronuncia una nueva verdad histórica: los archivos de su marido difunto encierran informaciones sobre acontecimientos disimulados por la historia nacional, en particular, en relación con la matanza de los indios Charrúas. Este es el pecado de hybris cometido por la joven nación y por decisión del Presidente Rivera.* Los Charrúas son una parte de la nación, los hechos retratados por una mujer, una voz menor de la Historia y trascriptos por ella en forma epistolar (género intimista por excelencia, como el diario), la llevan a identificarse con este sufrimiento colectivo. En la última secuencia de la novela la narradora exclama "Pero ahora agonizo". Chantraine-Braillon analiza la función del lector que reconstruye pasajes anteriores de la novela en función de esta declaración e interpreta el yo de Josefina como el eco de otras voces que parece asumir, paralelamente, la voz de Sepé, el cacique charrúa que agoniza pronunciando casi las mismas palabras, y la voz del coronel Bernabé, representante en la novela del poder político, quien también muere viéndose agonizar con la cara manchada de sangre. Tomás de Mattos ha querido mostrar con esa triada de voces que agonizan (actúan) en una (la de Josefina) el resultado de fuerzas en pugna, el diferendo político en un mismo cuerpo social, feminizado, la Patria definitivamente desmembrada. Lo que se conjuga en una voz son disidencias, la fuerza de tres voces en pugna recoge una forma nómada y nueva de la identidad nacional malherida. Ese yo de la coda, desde la intimidad de la protagonista de la novela, retoma la unidad dramática de la escena que representa el caos nacional. Nos interesa destacarlo en este trabajo sobre la literatura como representación susceptible de constituir un tipo de espejo que reproduce las transformaciones antropológicas e históricas de una sociedad en perpetuo movimiento. Más allá del mensaje singular de Josefina, sujeto escritor cuyas opciones (lugar desde donde escribe, competencias y motivaciones para hacerlo, punto de vista adoptado, modalidades de estilo) se revelan las huellas de transformaciones que toda escritura (grama) implica. Todo tipo de discurso así como su lectura pueden revelar una fotografía de la sociedad de su tiempo y, por lo tanto, son susceptibles de aportar conocimientos. Desde 
* (DARWIN, Charles R., op. cit., 1839.) ese punto de vista, podemos considerar como puestas al día, cada una en su época, estas representaciones en busca de sentidos de las fronteras poco delineadas, cambiantes del territorio americano: la contribución que hace Darwin al describir el paisaje, las ciudades, los pájaros, los carpinchos y unos fósiles "uruguayos".* asociadas en la lectura al relato de la Historia por Tomás de Mattos en ¡Bernabé Bernabé! muestran dos momentos de una composición (constelación) plural, que, como en el caso de los cuentos de Borges, indica cortes y cicatrices, vestigios de un horror apocalíptico que pueden declinarse (leerse) también como escenas de apacible pero intrigante cotidianidad en la que están relacionados los territorios y las políticas de las dos orillas del Río de la Plata como los dos lados de la frontera que separa Brasil de Uruguay.

Norah Giraldi Dei Cas es Catedrática de Literatura hispanoamericana en la Universidad de Lille (Francia). Miembro de CECILLE (Centre de recherches sur les Civilisations les Langues et les Littératures étrangères, Equipe d'accueil 3074), dirige el Seminario de investigaciones Les Amériques y el Programa Lieux et figures du déplacement de la red NEOS - NEWS Américas (Nords-Ests-Ouests-Suds), reconocido de interés científico por el Institut des Amériques (IDA Paris). Las últimas publicaciones en el marco de este Programa son : N. Giraldi Dei Cas - C. Braillon-Chantraine - F. Idmhand, (coord. e Introducción), Lugares y figuras del desplazamiento. Homenaje internacional a Fernando Ainsa, Un escritor entre dos mundos. Ediciones Iberoamericana, Madrid, 2010, 916 p.; T. Orecchia Havas N. Giraldi Dei Cas (coord. y prefacio), Sujets migrants : rencontres avec l'autre dans les imaginaires hispano-américains / Migrantes : encuentros con el otro en el imaginario hispanoamericano. Editeur P.I.E. Peter Lang, Bern, Collection Liminaires - Vol. 22, 2012, 326 p. ; N. Dei Cas Giraldi - C. Fourez - F. Idmhand (coord. y prefacio), Lieux et figures de la barbarie. Editeur P.I.E. Peter Lang, Coll. Comparatisme et Société, Bruxelles, 2012, 576 p. E-mail: < deicasgiraldi@skynet.be>. 